\title{
A Long Term Analysis of Two Undeniable Realities of the XXI Century - Global Economic Crisis and Demographic Aging
}

\author{
Alina Ștefania CHENIC (CREȚU) ${ }^{1}$ \\ Alin Ioan CRET $\mathbf{U}^{2}$ \\ Laurențiu TEȘCAN ${ }^{3}$
}

\begin{abstract}
The article highlights ideea which said that, in actuals socio-economics conditions, will appear inherently lethal mixture between two undeniable realities of the century, namely, on the one hand, economic and financial crisis, with immediate effects of restricting economic activities and thus drastically reducing job remuneration for work and, on the other hand, the trend of demographic aging in most civilized geopolitical zones, strong or medium economic developed. Mankind has lived a long time with the phobia of population explosion, as well as the phobia of premature death due to incurable medical conditions characteristic of the twentieth century but human medicine and the pharmaceutical industry have made remarkable progress. Life expectancy has increased continuously and spectacularly, especially in economically developed areas in Europe, North America, Asia and Australia. Along with this joyful reality, the civilized world has adopted an unexpected demographic trend, namely a massive reduction in the birth rate. Therefore, along with the trend at the beginning of this millennium - in which the civilized people marry and procreate a maximum of 1-2 children up to the age of 35 - after 2008, the global economic crisis appeared.

What will happen in the XXI century? Will the world's median age increase, dramatically reducing the ratio of people of working age and the total population? But the worst thing, in this context, seems to be the strangely inadequate reaction of human society regarding the use of available workforce. Many people of working age - often quite competent people-remain outside the labor market! Thus, this scientific approach constitutes a warning on the urgent and effective implementation necessity of new employment policies. On the contrary, we must accep that human civilization has finally found the brilliant and absolutely ridiculous model of self-destruction precisely because of the scientific and technical progress of medicine regarding the increase in life expectancy? Evolution involves regression?!
\end{abstract}

Keywords: aging population; reduce the birth rate; increasing life expectancy; civilized world; employment policies

JEL classification: F33, G28, J20

DOI: $10.24818 /$ RMCI.2018.2.196

${ }^{1}$ Alina Ștefania Chenic (Crețu), The Bucharest University of Economic Studies, Romania , E-mail: chenicalina@yahoo.com

${ }^{2}$ Alin Ioan Crețu, The Bucharest University of Economic Studies, Romania, Faculty of Theoretical and Applied Economics, 1st year, E-mail: cretu.alinioan@yahoo.com

${ }^{3}$ Laurențiu TEȘCAN, The Bucharest University of Economic Studies, Romania, E-mail: laurentiu_tescan@yahoo.com 


\section{Introduction}

A few decades ago, mankind is becoming increasingly aware of the imminent appearances of a apparently paradoxical phenomenon but unfortunately perfectly feasible, namely the self-destruction of terrestrial life. Worse, this grim reality scenarios is coming together with many other, more or less scientifically justified, more or less likely, taking into account various geophysical and cosmic catastrophes totally independent of the activities of human society - that may lead to sudden or gradual disintegration of life on our planet.

So far almost two decades, the so-called "cold war" between the Western/capitalist system led by US and the socialist/ communist headed by USSR, was the main reason for the human civilization anxiety - precisely because of the huge military arsenal classical nature destructive, nuclear, chemical and biological accumulated by the two global superpowers. After the 1990s, with the rise of the "Iron Curtain", the human civilization started to breath somewhat easier. But very soon the other elements already latent in progress, at the time of "cold war" ending, come from behind very threatening:

- Cybercrime, bioterrorism and nuclear terrorism, serious and real threats, generated on the first sight by the severe unilateral conflict of fanatical terrorist groups in the Muslim world against the West, mainly against the United States and its allies base. Very important to note is that this threat could be much enhanced by the escalating of geopolitical military conflicts, the reactivation of old conflicts or creating new ones because of other reasons. Probably, only a very wise and prudent approach of administrative economic and foreign military policies, from behalf of the leading world economic and military powers might diminish or even destroy these dangers.

- The imminence of a serious energy crisis of human civilization, driven by very rapid but gradual depletion of fossil energy resources, hydrocarbon solids, liquids and gases, base on which the humanity has built almost it's entirely technological and modern comfort. More than that, we have to point out that the use of nuclear energy as a viable alternative still remains as effective as it is dangerous because of extremely high destructive potential.

- Unprecedented food crisis has led and still leads the so-called biogenetic modification of human food - crisis related to the constant propagation of the human species, but further exacerbated by the inefficient use of available land and natural resources for livestock, horticulture, vegetable growing, viticulture, apiculture etc. On the other hand we have to mention the other crisis caused by massive unnecessary losses throughout the chain of production and consumption.

- Demographic crisis of the planet, the exponential growth of the human population -crisis mainly by the contribution of emerging and economically underdeveloped countries from Africa and Asia. Note that one of the countries with the 
greatest demographic impact, China, managed by severe family planning laws to blur sensitive this population growth.

- Pandemic Crisis - generated simultaneously by underdevelopment and overpopulation of particular geopolitical zones of the world with contagious effect of direct or indirect transmission into the whole civilized world, especially in the actual conditions of economic globalization and military multinationainterventionism in conflict. Beside a lot of severe infectious disease, often fatal, taken from these underdeveloped and overpopulated areas, over the past three decades it has appeared the terrifying virus HIV ehich is the latent trigger of AIDS.

- The profound biological crisis at the planetary level caused by the technological progress of modern civilization and the desire of expanding for life the planetary space and the affairs with disastrous effects on terrestrial ecosystems and marine. The immense forests surfaces were cleared for use as a timber material construction or fuel. In many other cases the deforestation often was cosed by the expanding of human settlements, road construction, urban construction planning, tourism, industrial, commercial, residential. Thus, in addition to the disastrous effects directly caused by vegetation reduction, vital for absorbing carbon dioxide from the atmosphere, it appeared the destruction of many plant and animal ecosystems which play an essential role in regulating biological planetary life.

- The developing and almost irreversible progressive so-called "greenhouse effect" caused by intensive human pollution of technologies and which goes to the destruction of the protective layer of ozone, having as a final result the well mediatized global warming pollution. Of course, it should be added that the effects of modern civilization pollution does not stop, it largely affects the pollution of surface and groundwater, soil and underground shaft.

As if it was not enough, over all these imminent "apocalyptic" planetary threats, recently a new crisis occurs suddenly hard to be explained at this stunning development of human civilization, the global financial crisis of 2007-2008, followed by a deep recession almost irreversible, strongly manifested at this moment 2013 .

Obviously, the direct and indirect effects of this immediate and devastating crisis are already strongly felt in most of the world. But what is difficult to see and especially to understand at this moment is the emergence of lethal mixture between two undeniable realities of the 21 century: on the one hand the above mentioned crisis with immediate effect of economic activities downsizing and thus drastically reducing employment and related remuneration and, on the other hand, the continuous trend of demographic aging in most civilized geopolitical zones, high or medium economic developed. From the demographical trend point of view, the world at the moment, with some notable exceptions, is divided into four separate categories, specific:

1. Zone with low / medium / high population density, but having a highly economic development level or representing rising emerging countries with a relatively 
modern civilization and advanced social consciousness - in which people perceiving the multitude of risks and social and economic disruption, are self-imposed a demographic future trend moderate to minim. In some cases, it is true that state demographic policy interventions are decisive in these aspects. Although this strategy is a logical first step, the combination of a low birth rate and an imminent increase in life expectancy due to modern conditions of life and work, especially due to advances in human medicine, leads to an extremely aging of the population. In this category can be assigned: Western Europe, Russia, US, Canada, Australia and New Zealand, some countries in the Middle East and Middle East and also some highly populated Asian countries like China, Japan, South Korea, Singapore, etc.

2. Zones with population with small/medium density having a relatively low economic development representing moderate rising emerging economies where people perceiving great present difficulties in economic and social plan are selfassessing also a growing demographic trend from moderate to minimal. As previously, reduced birth rate appears here as an immediate imperative, much enhanced by very weak policies of increasing birth rate. Somehow surprising in these states however, the life expectancy is quite high, even if the conditions of life and work are relatively difficult without taking into account the huge deficiencies of health care. Of course, the demographic assumptions of population aging appear even here. In this category can be included the countries of South -Eastern Europe and the Baltic States before 1990 which were part of " Soviet Empire " as well as the vast majority of countries in Latin and Central America. It could be added a number of north African Mediterranean countries, such as Egypt, Algeria, Morocco, etc. and also a few countries in the Middle East.

3. Over populated and rising population areas of the world - representing strong emerging countries such as India , Brazil, Mexico, Turkey and countries with large natural resources, particularly oil such as Iran, Iraq, Kuwait, Qatar, Saudi Arabia and the UAE. These are countries where the birth rate will remain about the same level until 2050 or will face a relatively small decline, but which will be contributing dramatically to increase the planetary population. It can be appreciated that in these areas the risk of aging population will be much smaller, taking into account the average life expectancy and today average age. All these countries have a median ranged between 25 to 30 years and a life expectancy between 67-77 years.

4. 4.The very poor geographical and / or economically weak and the whole area of Saharan and sub-Saharan African continent, Central America, much of Latin America, mostly part of Asia region including the Asian area of former Soviet Union (except Arab countries, China, Japan, Singapore and South Korea). These countries, with very few exceptions - occupy the first 150 ranking positions of top birth rate in the world (out of a total of 220 countries). Obviously their share in world population growth will be major. If for the states included in the previous paragraph, the 
demographic policy is logical and follows a common sense, for the last category, the population explosion is seemingly implausible and of course without any governmental control. More than that, we have to take into account that infant and post infant rate death is alarming, not to discuss the low average life expectancy in the context of working and living in conditions very difficult and risky, sustained by an incipient medical health insurance.

Interesting to note is that this population growth is usually inversely proportional to the economic development of the respective geopolitical zones, yet is based on some cultural and religious concepts about procreation. In fact it is quite likely that very high level of infant / post infant mortality in these areas have led to an unconscious instinct of survival, similar to the animals, which procreate a large number of fetuses to ensure continuity of species.

From the demographic experts point of view who study the world population trends forecast on the twenty-first century at the UN command, there are three possible scenarios represented in next figure, depending on the evolution of the real effective birth rate in the future:

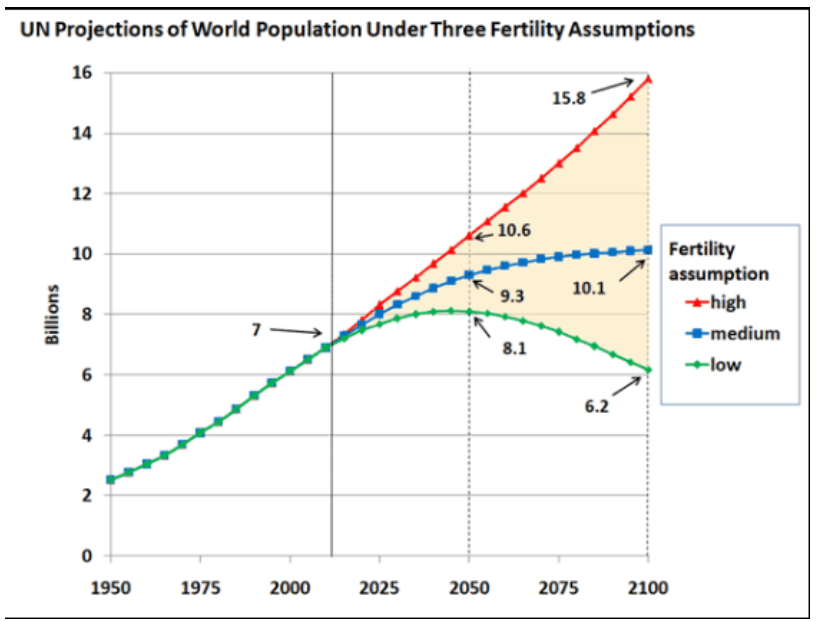

Figure 1 World Population Prospects: The 2012 Revision. New York: United Nations. Source: Population Division of the Department of Economic and Social Affairs of the United Nations Secretariat (2013).

The red curve is shown the high- variant version in which it would be maintained the average rate of evolution available until 2012. In this case, at the end of the century, the world would reach the figure of about 15,8 billion people, compared with about 7 billion today. Overpopulation will be huge on the planet with an optimal 
median age - but which will actually drain energy, mineral resources, and sources of drinking water supply of the planet.

The curve depicted in blue, corresponds to the current demographic trends described above - leading to an expected to medium variant, corresponding to a moderate increase in world population which will reach around 10.1 billion habitants until the end of the century. Although a substantial increase, it is well below the high version and it seems to be a point beyond which there is no possible increase in the next century, but a situation which will bring a an appreciable aging of planet population.

The green curve is the low variant valid in the case in which even the most prolific countries are reassessing their policies in terms of demographic and socioreligious attitudes. This situation will lead towards the end of the century to a population of around 6.2 billion people - surprising less than current population, but having a clear downward trend in the next century.

This last option seems to be the ultimate and most realistic in terms of probability, taking into account the possibility of military classical ethnic or geopolitical conflict, or any other armed interventions that would lead to regression of number of young people, potential combatants.

As shown in the interpretation of demographic forecasts global perspectives, there is no optimal solution. Avoiding the hazard of global population explosion will bring necessarily the population aging. In this context we must consider the immediate and long term solutions having in mind the socio-economic aspects of the civilized world on this issue.

\section{Aging of Population - the Catastrophic Socio-Economic Effects for Humanity}

We restate the previously expressed idea in the introduction of this article which said that will appear inherently lethal mixture between two undeniable realities of the century, namely, on the one hand the economic and financial crisis, with immediate effects of restricting economic activities and thus drastically reducing job remuneration for work and, on the other hand, the trend of demographic aging in most civilized geopolitical zones, strong or medium economic developed. For highlighting the overall aging population, the following diagram presents the forecasted evolution of the growth rate world's population during 1950-2050 and in parallel the increase population in absolute number over 1700-2050 time period. 


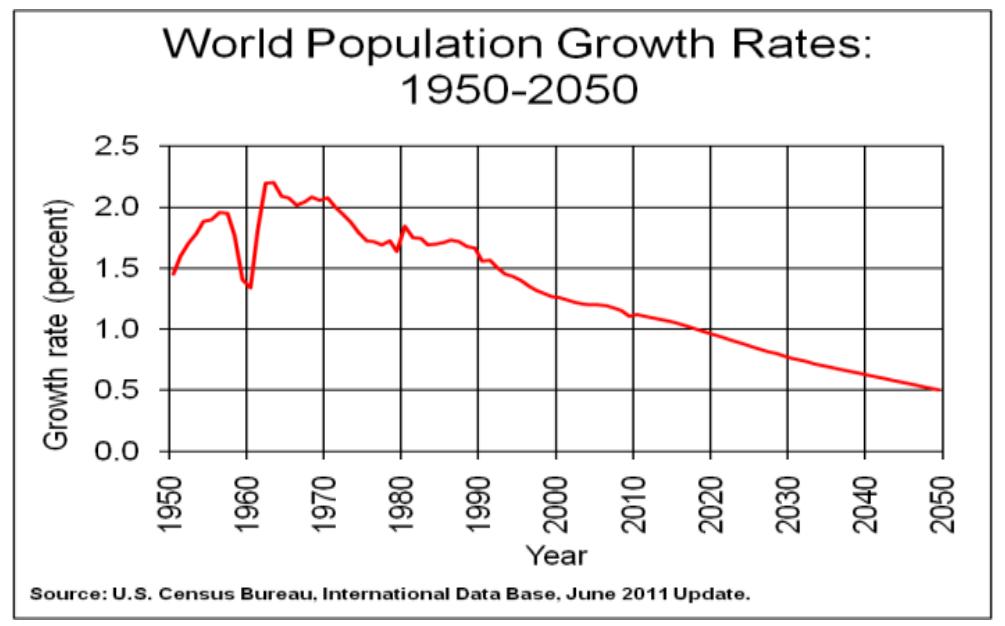

Figure 2 World Population Growth Rates 1950 - 2050

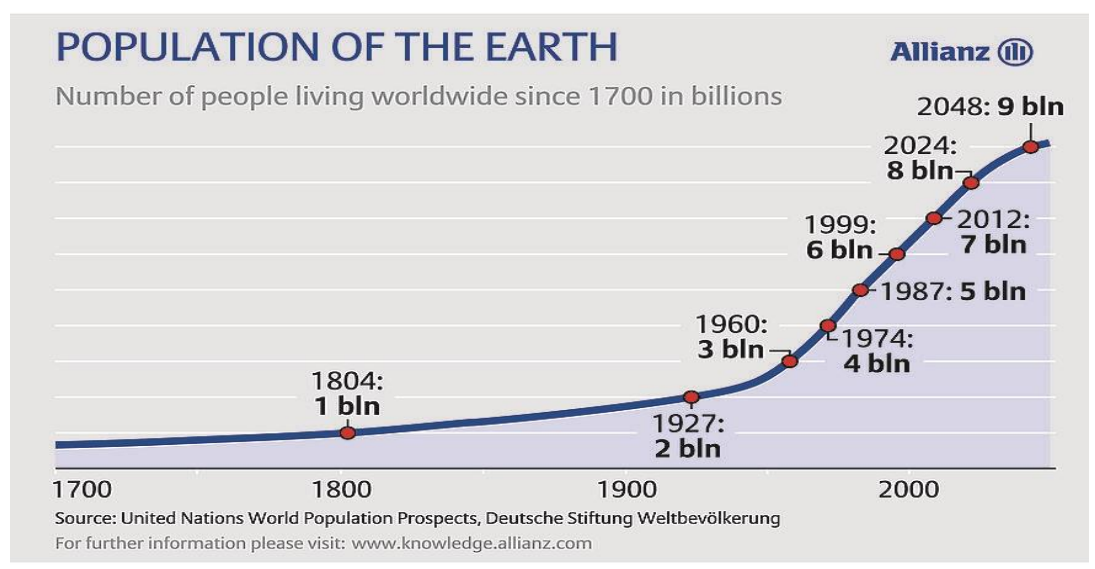

The publication of this graphic is free of charge provided that users credit Allianz SE. Graphics are available in the media section of the Allianz Knowledge Site. www.knowledge.allianz.com/en/media/graphics

\section{Figure 3 Population of the earth}

As easily observed the percentage rate of growth in the mid of twenty-first century will be at a value of around 4-5 times lower than the peak from 1960-1970 period. In fact, from a careful comparative analysis of the two resulting graphs, we can conclude undoubtedly about the overall aging of population phenomenon. 
From the next two diagrams we can observe the percentage rate dispersion of human population growth of different geopolitical and geographic areas, from 2011 to 2050. It becomes obvious that even for this minimal percentage rate of global growth will be entirely due to the very poor countries or in the best case to developing countries from Africa, Southwest Asia, the Arabian Peninsula Zone, and zone IndiaPakistan -Bangladesh, Indonesia, Indochina, Latin America and southern part of North America. In 2050 it appears that the most intense and concerning population growth will be given by the African continent and the most impoverished regions of Asia.

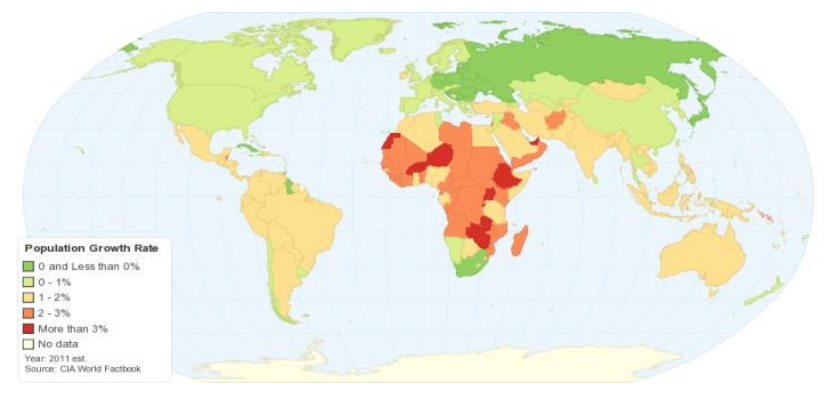

Figure 4 The total fertility rate

Note: The total fertility rate measures the total number of children a woman would have given current birth rates.

Source: C. Haub and M.M. Kent, 2008 World Population Data Sheet

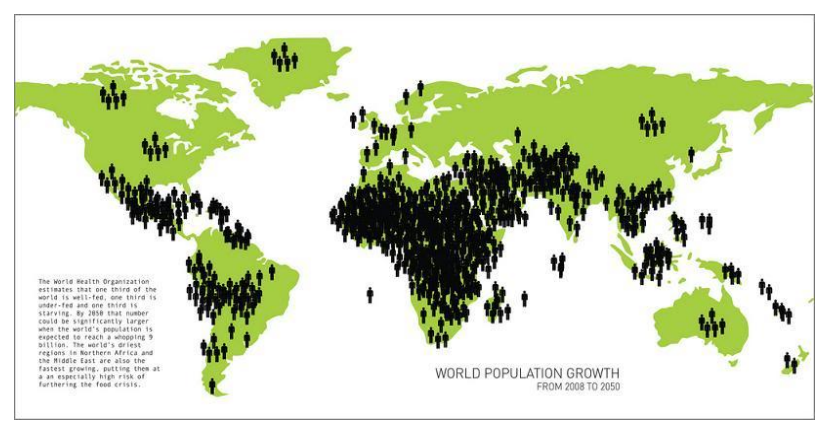

Figure 5 World population growth trend by country - 2008-2050

Note: World population growth trend by country - 2008-2050

Source: The World Health Organization, 2008 
The following diagram clearly shows that for next year available until the middle of the XXI century massive global population growth will be increasingly more poor countries and / or emerging ones.

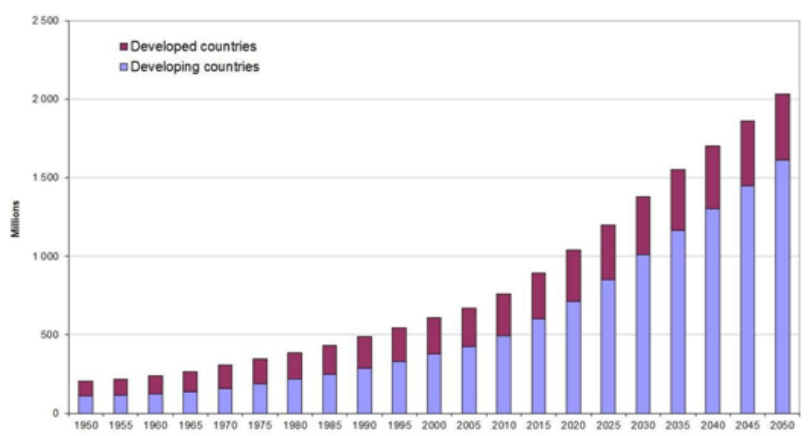

Figure 6 Global population growth

Note: The group of "developed countries" corresponds to the "more developed regions" of the World Population Prospects: The 2010 Revision, and the group"developing countries" corresponds to the "less developed regions" of the same publication

Source: UNDESA, World Population Ageing 2011 (2012; forthcoming), based on UNDESA Population Division medium projection scenario, World Population Prospects: The 2010 Revision.

For the geographic areas with a very low growth rate or almost zero or even negative - the process of population aging will be a quite unbearable in terms of socio -economic policies without adopting a very strong employment and labor policies and a massive openness for immigrants. According to the chart below which shows the share of persons equal to or greater than 60 years age in the total population, noticeable is the fact that aging population percentage will increases worldwide reaching to the level of $5-20 \%$ in 2012 to values of $12.5-35 \%$ in 2050 : 


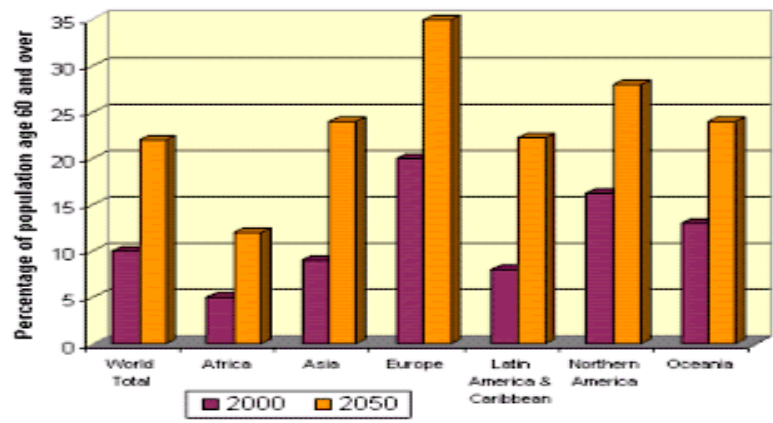

Figure 7 Share of persons equal to or greater than 60 years age in the total population

Note: Percentage of world population age 60 and over.

Source: World Population Prospects: The 2012 Revision | United Nations Population Division

To emphasize the extreme difficulty generated by aging population for the states affected by this phenomenon, we present furthermore the arguments that seem to be really essential and decisive:

- Even though, at first glance, the reaction of governments and legislative bodies at the national or Community level, as an answer for this alarming demographic trend is lifting the threshold limit of normal or early retirement, the solution is just theoretical. This is because the realities of national, European and even global employment area looks absolutely clear that unemployed people over 50 years or sometimes even over 45 years are facing immense difficulties of re-employment after losing their previous job because they are considered as having less to offer on the labor market. Under these circumstances how can we consider that raising the bar for the 70-75 retirement years would be an inevitable response to the aging population crisis?

- If besides the extreme difficulty of reemployment for the persons over 4550 years of experience with a training at least acceptable, we are adding to the difficulties of finding a job for graduates of technical colleges, vocational schools or other institutions of average education level and even many institutions of higher education - we reach a new level of critical occupancy rate of population. Contrary with the first category presented formed by elderly people, in the specific case of young graduates, the difficulty of employment is caused by lack of the minimum professional acceptable experience.

- Minimizing the contribution of groups of 45-65 years and 15-25 years respectively, from the working population, it remains a maximum of $60 \%$ of the people accepted on the labor market. If we are adding the groups of $0-15$ years and +65 , we find that a variable percentage up to $45-50 \%$ of the population is within the acceptable 
optimal accepted on the labor market. We have to admit that this $45-50 \%$ represent a maximum of total employment gap from an optimal of 25-45, because an appreciable proportion avoids to work, choosing to go for illegal, unlawful, antisocial, or simply hard deductible income - apparently legal, which brings superior gains partially or totally exempt from taxes. This people forming the "black market" and the so-called informal labor sector which decrease the percentage mentioned above to around $35-40 \%$.

- A relatively small but yet measurable by the persons with an optimal age for working but which presented various diseases, disabilities and physical or neurological disabilities. Adding to this segment, apparently narrow, a broad segment of persons with optimal age to work, 25-45 years, but with training, skills, abilities and experience that make them difficult to be employed, we are reaching to a maximum percentage of actual third between formal employment and population.

- Obviously, it appears the following option which is already used more or less extensively from one state to another depending on its economic capacity: the acceptance of Asians immigrants which represents an important part from a human resource balance sheet. It is a viable option, but frequently limited to informal work or serious work with routine or unskilled labor. This is because usually, the human resource comes from economically weak areas or strong areas of emerging powers but with a limited absorption degree of labor (ex. China and India).

Having in mind the current demand and especially the immediate future demand of the world economy, the modern labor market require more and more workers with high or at least average skills, high communication, language, computer and information technology skills. Therefore, the solution of massive immigration is limited especially because of quality of imported labor.

However, some economically powerful countries like the U.S. will opt massive and continuing to this solution and consequently the demographic profile of the U.S. will change dramatically in the middle of this century, according to new population projections developed by the Pew Research Centre.

\section{Conclusions}

The correct and complete awareness of the devastating socio-economic effects generated by perfectly transparent real phenomenon of demographic aging - is the first and the most important step for blurring or annihilation of these effects. Although, much publicized and analyzed, the demographic aging phenomenon is not fully aware by governments. Otherwise it can not be explained the political, legislative and administrative ineffective and mostly totally inadequatelly approaches, sometimes even contradictory, addressed to this global problem, but, especially, to European problem. 
We should be aware that a real and effective improvement of public employment work will bring an economic development, an increased quality of life, indirectly, a real impetus for increasing the birth rate and more solid economic and financial support for its growth in the sense of providing substantial parenting allowance, strictly imposed by the fair and full parental obligations. Perhaps, if talk about demographic aging, the most intelligent measure that would be able to take, will be the implementation of efficient growth employment policies for the people 45-46 aged and even over 65 . Certainly such approach would significantly defuse the demographic aging issue and the anxiety status generated by this inherent phenomenon who features the developed human civilization. Any other approach would not justify the immense progress of human civilization available - progress that has led to the dramatic increase of life expectancy, through the development of medicine, work and life's conditions. Even forced artificially increasing through legislative and financial measures of birth rate from civilized states, even increased migration from geographic areas with surplus of youngs and even more the grotesque reduction of life expectancy is not the expected answer by human society of the XXI century.

\section{References}

1. European Commision (2012): The 2012 Ageing Report Economic and budgetary projections for the 27 EU Member States (2010-2060)-European Economy 2|2012

2. European Comission (2013): The EU in the world 2013-A statistical portrait

3. European Commision - Directorate-General for Economic and Financial Affairs 2012 The 2012 Ageing Report: Underlying Assumptions and Projection Methodologies Joint Report prepared by the European Commission (DG ECFIN) and the Economic Policy Committee (AWG) 4/2011

4. Ahn, N., Garcia, J.R. and Herce, J.A. (2005), "Demographic Uncertainty and Health Care Expenditure in Spain", Documento de Trabajo 2005-07, Paper for the project DEMWEL (Demographic Uncertainty and the Sustainability of Social Welfare System) financed by the European Commission, 5th Research Framework Programme.

5. Australian Productivity Commission (2005), 'Economic Implications of an Ageing Australia', Research Report, Canberra, Australia.

6. Baldacci E. and D. Tuzi, (2003), 'Demographic trends and pension system in Italy: an assessment of 1990s reforms', in Labour, No. 17, vol.17, special issue.

7. Batljan, I. and Lagergren, M., (2004), "Inpatient/outpatient health care costs and remaining years of life. Effect of decreasing mortality on future acute health care demand", Social Science and Medicine, Vol.59, pp. 2459-2466. 
8. Brugiavini A. and F. Peracchi (2005), "Fiscal implications of pension reforms in Italy", in Gruber J; and D; A. Wise (editors)(2005), "Social Security Programs and Retirement around the World: Fiscal Implications", NBER Website. 26 July 2005.

9. Brugiavini A. and F. Peracchi (2003), "Wealth and Retirement decisions", Labour, Volume17, Special Issue, Blackwell Publishing.

10. Burniaux J., M., R. Duval and F. Jaumotte (2003), 'Coping with ageing: a dynamic approach to quantify the impact of alternative policy options on future countries', OECD Economic Department Working Papers, No. 371.

11. Busse R., Krauth, C. and Schwartz, F.W., (2002), "Use of acute hospital beds does not increase as the population ages: results from a seven year cohort study in Germany", Journal of Epidemiology and Community Health 2002, Vol. 56, pp. 289-293.

12. Börsch-Supan A. (2003), 'Labor market effects of population aging', Labour, Vol. 17, Special Issue, Blackwell Publishing.

13. Carone G. (2005): 'Long-term labour force projections for the EU25 Member States: a set of data for assessing the impact of ageing', DG ECFIN, European Economy, Economic Papers No. 235.

14. Carone G., D. Costello, N. Diez Guardia, G. Mourre, B. Przywara, A. Salomaki (2005), 'The economic impact of ageing populations in the EU25 Member States', DG ECFIN, European Economy, Economic Papers No. 236.

15. Carone G., Denis C., McMorrow K., Mourre G. and W. Röger (2006), "Longterm labour productivity and GDP projections for the EU25 Member States: a production function framework", DG ECFIN, European Economy, Economi Papers, No. 253. 304Comas-Herrera, A., Wittenberg, R. and L. Pickard (2005): "Making projections of public expenditure on long-term care for the European member states Methodological proposal for discussion", paper presented at the Commission- AWG-OECD workshop on 21-22 February2005.

16. Denis C., D. Grenouilleau, K. Mc Morrow and W. Röger (2006): 'Calculating potential growth rates and output gaps - A revised production function approach', DG ECFIN European Economy, Economic Papers No. 247.

17. Dolbhammer, G. and Kytir, J., (2001) "Compression or expansion of morbidity? Trends in healthy-life expectancy in the elderly Austrian population between 1978 and 1998", Social Science \& Medicine, Vol. 52, No. 3, pp. 385-391.

18. Downes, J., A. Drew and P. Ollivaud (2003), 'The OECD medium-term reference scenario: economic outlook', OECD Economics Department Working Papers, No. 372, Paris.

19. Duval R. (2003), 'The retirement effects of old-age pension and early retirement schemes in OECD countries', OECD Economic Department Working Papers, No. 370. 
20. Dybczak K. and B. Przywara (2010): 'The role of technology in health care expenditure in the EU', DG ECFIN, European Economy, Economic Papers No. 400.

21. Economic Policy Committee (2003a), 'The impact of ageing populations on public finances: overview of analysis carried out at EU level and proposals for a future work programme', EPC/ECFIN/407/04-rev.3-EN of 22 October 2003.

22. Economic Policy Committee (2008), 'The 2009 budgetary projection exercise of the Ageing Working Group: Second progress report to the EPC', ECFIN/CEFCPE(2008)REP/ 52951 rev, Brussels, 23/06/2008.

23. Economic Policy Committee and European Commission (2005), "The 2005 EPC projections of age-related expenditure (2004-2050) for the EU25 Member States: underlying assumptions and projection methodologies" in European Economy Reports and Studies, No. 4.

24. Economic Policy Committee and European Commission (2008), "The 2009 Ageing Report: Underlying Assumptions and Projection Methodologies for the EU-27 Member States (2007-2060)" in European Economy. No. 7. December 2008.

25. Economic Policy Committee and European Commission (2006), 'The impact of ageing on public expenditure: projections for the EU25 Member States on pensions, health care, longterm care, education and unemployment transfers (2004-2050)', European Economy, Special report, No. 1/2006.

26. Economic Policy Committee and European Commission (2009), The 2009 Ageing Report: Economic and budgetary projections for the EU-27 Member States (2008-2060)', European Economy. No. 2. April 2009.

27. Economic Policy Committee and European Commission (2007) "Pensions Schemes and Projection Models in EU-25 Member States", European Economy, Occasional papers No. 35, November 2007.

28. European Commission (2006), 'The long-term sustainability of public finances in the European Union', European Economy, No. 4/2006.

29. European Commission (2008a), 'Economic forecast - Spring 2008', European Economy, No.1/2008.

30. European Commission (2008b), 'Public finances in EMU in 2008', European Economy, No. 4/2008.

31. Economic Policy Committee and European Commission (EPC/EC) (2009), The 2009 Ageing Report: economic and budgetary projections for the EU-27 Member States (2008-2060), European Economy, No. 2/2009, Directorate General Economic and Financial Affairs,

32. European Commission - DG ECFIN (2011a), "Health and long-term care expenditure projections: availability/collection of data", Note for the attention of the Ageing Working Group of the EPC, ECFIN/C2(2011)128176. 
33. European Commission - DG ECFIN (2011b), "Long-term care expenditure projections: methodology and main assumptions", Note for the attention of the Ageing Working Group of the EPC, ECFIN/C2(2011)545542

34. Eurostat (2004), 'Classification of funded pension schemes in case of government responsibility or guarantee', News release 30/2004, 2 March.

35. Eurostat (2005a) 'EU25 population rises until 2025, then falls', Eurostat press release448/2005 of 8 April 2005.

36. Eurostat (2005b), 'AWG ad hoc scenario', presentation to the AWG meeting of 16 June 2006.

37. Eurostat (2008a), "Ageing characterises the demographic perspectives of the European societies", Statistics in Focus, No. 72/2008.

38. Eurostat (2008b), "Population projections 2008-2060. From 2015, deaths projected to outnumber births in the EU27", News release No. 119/2008, 26/8/2008. EUROPOP

39. Eurostat (2009), "Methodology and main results of the Eurostat Population Projections 2008- based (EUROPOP2008)", Eurostat, Methodologies and Working Papers series, Luxembourg, forthcoming

40. Eurostat (2011), 'Eurostat Population Projections 2010-based 'EUROPOP2010': Methodology and results of a long-term scenario of demographic convergence (forthcoming).

41. Fries, J.F., (1989), "The compression of morbidity: near or far?", Milbank Memorial Fund Quarterly, Vol. 67, pp. 208-232.

42. Fries, J.F., (2005), "The compression of morbidity", Milbank Quarterly, Vol. 83, No.4, pp. 801-823.

43. Gabriele, S., Cislaghi, C., Costantini, F., Innocenti, F., Lepore, V., Raitano, M., Tediosi, F., Valerio, M. And Zocchetti, C., (2005), "Demographic factors and health expenditure profiles by age: the case of Italy", Societa Italiana di Economia Pubblica, Dipartmento di Economia Pubblica e Territoriale, Universita di Pavia.

44. Getzen, T.E., (2000), "Health care is an individual necessity and a national luxury: Applying multilevel decision models to the analysis of health care expenditures", Journal of Health Economics, Vol. 19(2), pp. 259-270.

45. Gruber J and D.A. Wise (editors) (2005b), 'Social Security Programs and Retirement around the World: Fiscal Implications', NBER Website. 26 July 2005. http://www.nber.com/books/intlSS-p3/index.html.

46. Gruenberg, E.M., (1977), "The failure of success", Millbank Memorial Fund Quarterly, Vol., 55, pp. 3-24.

47. Hatton, T. J. and J. G. Williamson (2003), "What fundamentals drive world migration?" Discussion Paper No. 2003/23, United Nations University/World Institute for Development Economics Research, March. 
48. Jagger, C., Matthews, R., Matthews, F., Robinson, T., Robine, J.M, Brayne C. and the Medical Research Council Cognitive Function and Ageing Study Investigators., (2007), "The burden of disease on disability-free life expectancy in later life", The Journals of Gerontology series A, Biological Sciences and Medical Sciences, Vol. 62, No. 4, pp. 408-414.

49. Lafortune, G. and Balestat, G. and the Disability Study Expert Group Members., (2007), "Trends in severe disability among elderly people: assessing the evidence in 12 OECD countries and the future implications", OECD Health Working Papers No. 26, OECD.

50. Latulippe D. (1996) "Effective retirement age and duration of retirement in the industrial countries between 1950 and 1990", ILO, Issues in Social Protection DP No. 2.

51. Lanzieri (2011), 'The Greying of the baby boomers: A century-long view of ageing in European populations', Eurostat, Statistics in Focus 23/2011.

52. Madsen M. (2004), "Methodologies to incorporate 'death-related' costs in projections of health and long-term care based on Danish data", Ministry of Finance, Denmark.

53. Montanino A., B. Przywara and D. Young (2004), "Investment in Education: the Implications for Economic Growth and Public Finances", European Economy, Economic Papers, No.217.

54. Mor, V., (2005), "The compression of morbidity hypothesis: a review of research and prospects for the future", Journal of the American Geriatrics Society, Vol. 53, No.9, pp. s308-S309.

55. OECD (2003), 'Labour force participation of groups at the margin of the labour market: past and future trends and policy challenges', Working Party $\mathrm{N}^{\circ} 1$ on Macroeconomic and Structural Policy Analysis, ECO/CPE/WP1(2003)8.

56. OECD (2006), Costs of Care for Elderly Populations. Guidelines for estimating long-term care expenditure, DELSA/HEA/DIS(2006)4, 14 February 2006.

57. OECD (2007), Data collection on long-term care (focussing on recipients), Meeting of OECD Health Data National Correspondents, DELSA/HEA/HD(2007)7, 28 September 2007.

58. Polder, J.J., Barendregt, J.J. and Van Oers, H., (2006), "Health care costs in the last year of life - The Dutch experience", Journal of Social Science \& Medicine, Vol. 63, Issue 7, October 2006, p. 1720-1731.

59. Raitano, M. (2006), "The Impact of Death-Related Costs on Health-Care Expenditure: A Survey", ENEPRI Research Report No. 17.

60. Robine, J.M and Michel, J.P., (2004), " Looking Forward to a General Theory on Population Aging", The Journals of Gerontology, series A, Biological Sciences and Medical Sciences, Vol. 59 No. 6, pp. M590-M597. 
61. Robine, J.M., Jagger, C., Mathers, C.D., Crimmins, E.M. and Suzman, R.M., (2003a), "Trends in health expectancies", in Robine, J.M., Jagger, C., Mathers, C.D., Crimmins, E.M. and Suzman, R.M., (eds), Determining Health Expectancies, John Wiley \& Sons, Ltd, Chichester, UK.

62. Scherer P. (2002), 'Age of withdrawal from the labour force in the OECD countries', Labour Market and Social policy Occasional Papers, No.49-DELSA.

63. Schmertmann C. (2003), "A system of model fertility schedules with graphically intuitive parameters", Demographic Research, 9:81-110.

64. Schmertmann C. (2005): "Quadratic spline fits by nonlinear least squares", Demographic Research, 12:105-106.

65. Seshamani, M. and Gray, A.M. (2004), "A longitudinal study of the effects of age and time to death on hospital costs", Journal of Health Economics, Vol. 23, No. 2, pp. 217-235.

66. Siegel J.S. and Swanson D.A. eds. (2004), "The Methods and Materials of Demography", 2nd ed. Elsevier Academic Press, San Diego (USA).

67. Solow, R. M. (1956), "A Contribution to the Theory of Economic Growth", Quarterly Journal of Economics, No.70, pp. 65-94.

68. Suhrcke, M., Fumagalli, E. and Hancok, R., (2010) "Is there a wealth dividend of aging societies", Public Health Reviews, Ageing Societies, Vol. 32, No. 2.

69. United Nations (2004), "World Population Prospects - The 2002 Revision", volume III: Analytical Report.

70. United Nations (2008), "World Population Prospects: The 2006 Revision", Population Division of the Department of Economic and Social Affairs of the United Nations Secretariat.

71. United Nations (2010), "World Population Prospects: The 2008 Revision", Population Division of the Department of Economic and Social Affairs of the United Nations Secretariat.

72. Verbrugge, L.M., (1984), "Longer life but worsening health? Trends in health and mortality of middle-aged and older persons", Milbank Memorial Fund Quarterly, Vol. 62, pp. 475-519. 